\title{
Knowledge Acquisition for Knowledge-Based Systems: Notes on the State-of-the-Art
}

\author{
JOHN H. BOOSE \\ Advanced Technology Center, Boeing Computer Services, 7L-64, PO Box 24346, Seattle, \\ Washington, 98124, USA \\ BRIAN R. GAINES \\ Department of Computer Science, University of Calgary, 2500 University Dr. NW, Calgary, \\ Alberta, Canada T2N $1 N 4$
}

\begin{abstract}
Notes from the organizers of a series of knowledge acquisition workshops are presented here. The state-of-the-art in knowledge acquisition research is briefly described. Then the technology of interactive knowledge acquisition is discussed, including a descriptive framework, dimensions of use, and research patterns. Finally, dissemination of information from knowledge acquisition workshops is detailed.
\end{abstract}

Key Words: knowledge acquisition, knowledge acquisition tools, knowledge acquisition methods, knowledge-based systems, expertise transfer, knowledge elicitation.

\section{Knowledge Acquisition-State-of-the-Art}

At the time of the first AAAI Sponsored Workshop on Knowledge Acquisition for KnowledgeBased Systems in Banff, November 1986, the literature on knowledge acquisition was sparse, scattered in conference publications, and difficult to access. The 1986 Workshop and the ensuing journal publication of some forty papers representing the state-of-the-art world-wide changed that situation. The inclusion of sessions on knowledge acquisition in many conferences, the European Workshops on Knowledge Acquisition for Knowledge-Based Systems in London and Reading, September 1987, Bonn in June 1988 and Paris in July 1989, the Banff Workshops in October 1987, November 1988 and October 1989, and the establishment of a new knowledge acquisition journal (see below) have changed the situation even further. We now have a worldwide network of communicating researchers aware of one another's activities and an open, widely disseminated and readily available literature on knowledge acquisition.

The problem now is not so much to access research and experience in knowledge acquisition, but to make sense of the diverse and wide-ranging material available and, in particular, to apply the results to improve effectiveness in the development of knowledge-based systems. There are major impediments to such understanding and application:

- A diversity of techniques and tools that overlap in their applications but that may be either competitive alternatives or complementary partners

- Lack of variety, detail, and evaluation in the case histories of applications of the techniques and tools 
- Lack of access to the techniques and tools outside the narrow research communities originating them

- Lack of standardization in the knowledge representation resulting from the techniques and tools, making it difficult to integrate them and to interface them to existing knowledgebased systems

- Lack of standardization in the forms of data required by the techniques and tools making it difficult to apply them in the same situation and compare them

- Lack of standardization in the user interfaces to the interactive tools making it difficult to integrate them in an effective environment for human-computer interaction

- Lack of portability in the run-time environments required by the tools making it difficult to integrate them with other systems

These are not unreasonable problems at this stage of development of knowledge-based systems. We are in the midst not only of the evolution of a rapidly developing technology but a revolution of our understanding of the nature of knowledge and knowledge processes in society and technology. Premature standardization resulting in over-rigid systems would be inappropriate and a major impediment to progress. However, we have to balance the need for integration, dissemination, and application of knowledge acquisition techniques and tools against the dangers of rigidity.

\subsection{Knowledge Acquisition in Context: Knowledge-Based System Technologies}

Knowledge acquisition can be considered as one further technology contributing to the development of knowledge-based systems (KBS). Figure 1 places it in the context of the related technologies which make up the virtual machine hierarchy of existing KBS.

- Knowledge Support System: at the top of the hierarchy are experimental systems integrating knowledge acquisition and performance tools in systems designed to support knowledge base updating and extension as part of ongoing applications.

- Knowledge Acquisition Tools: at the next level are the tools for automating knowledge engineering for KBS, through automatic interview procedures, modeling expert behavior, and analysis of knowledge in textual form.

- Knowledge-Based System Support Environment: at the third level of the hierarchy is the equivalent of the Application Programming Support Environment (APSE) in conventional systems, with facilities for editing, displaying, debugging, and validating the knowledge base.

- Knowledge-Based System Shell: at the fourth level of the hierarchy is the knowledgebased system shell as a run-time environment that elicits problem-specific information from the user, provides advice based on its knowledge base, and explains that advice in as much detail as required.

- Shell Development Language: at the fifth level of the hierarchy is the language in which the knowledge-based system shell is written, generally a special-purpose environment for coping with knowledge representation and inference. 


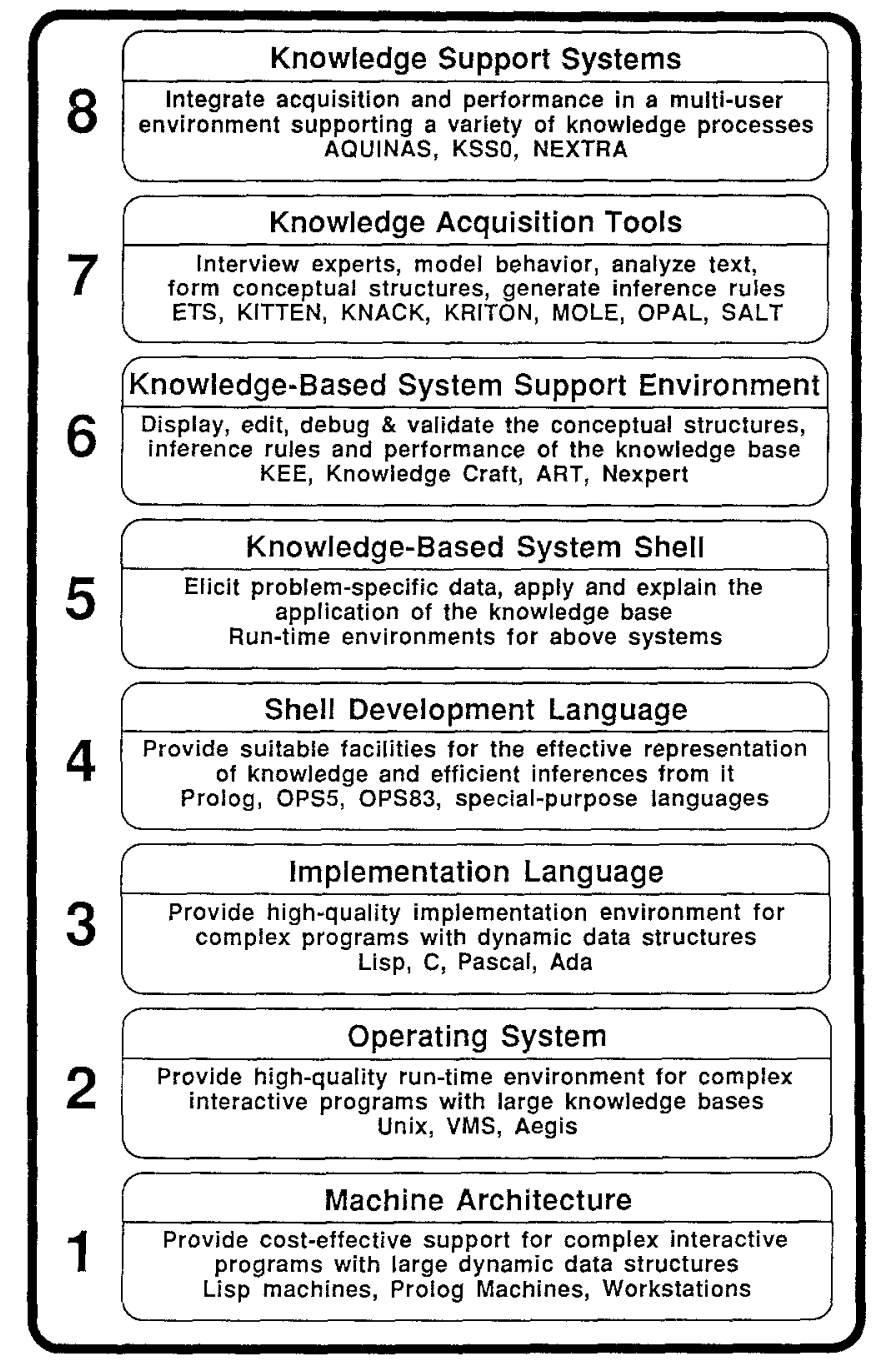

Figure 1. Knowledge-based systems virtual machine hierarchy.

- Implementation Language: at the sixth level of the hierarchy is the implementation language which actually interfaces to the computer. This tended to be Lisp in the early days of KBS, but as speed and space efficiency have become significant and knowledge representation has become better understood, other languages that support dynamic data structures such as $\mathrm{C}$ and Pascal have become widely used.

- Operating System: at the seventh level of the hierarchy is the operating system within which the implementation runs. This needs to provide good interfaces to other programs, large databases and communications. 
- Machine Architecture: at the lowest level of the hierarchy is the machine on which the KBS runs. In theory, system developers should not need to know about the lower levels of the hierarchy-machine architectures, operating systems, and implementation languages are remote from knowledge processing. In practice, these lower levels are the foundations on which systems are built, and any defects in them can undermine the functionality of the upper levels.

\subsection{Trends in Knowledge Engineering}

The basic model for knowledge engineering has been that the knowledge engineer mediates between the expert and knowledge base, eliciting knowledge from the expert, modeling and encoding it for the knowledge base, and refining it in collaboration with the expert to achieve acceptable performance. Figure 2 shows this basic model with manual acquisition of knowledge from an expert followed by interactive application of the knowledge with multiple clients through an expert system shell.

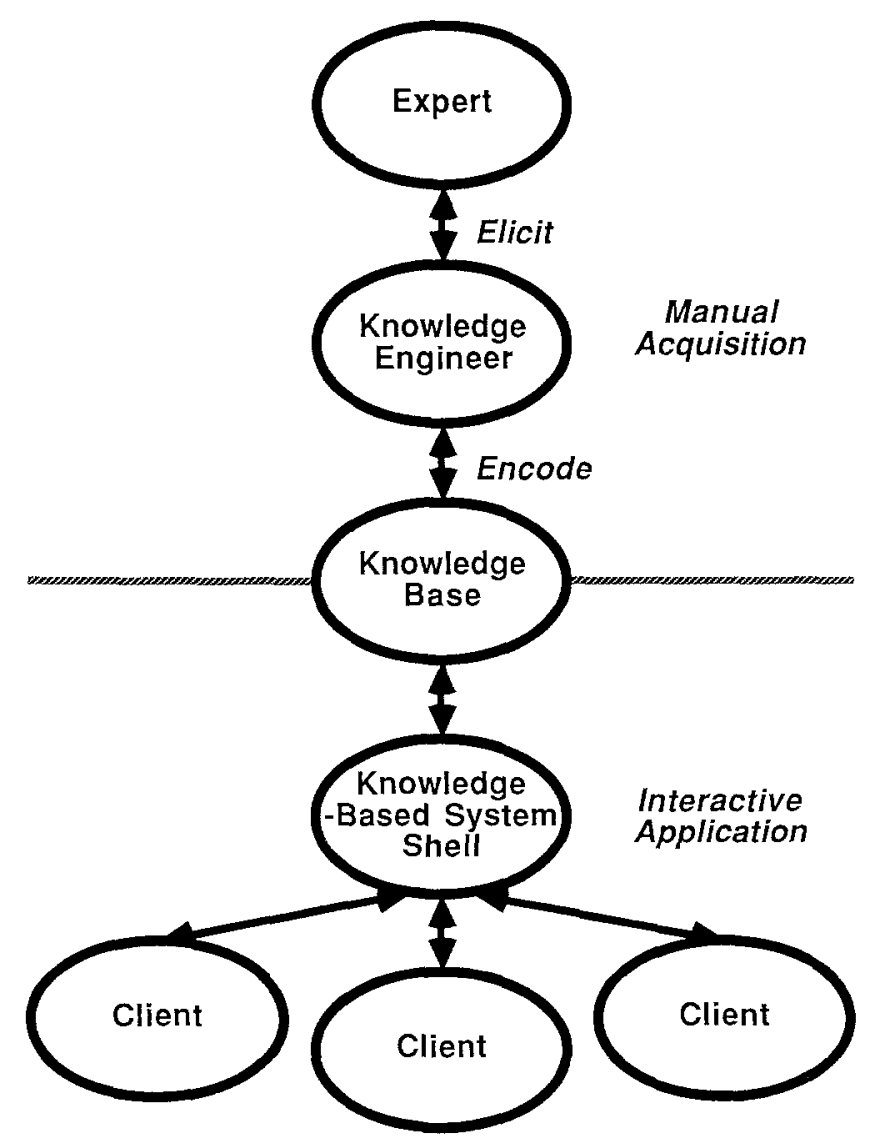

Figure 2. Basic model of manual knowledge acquisition. 


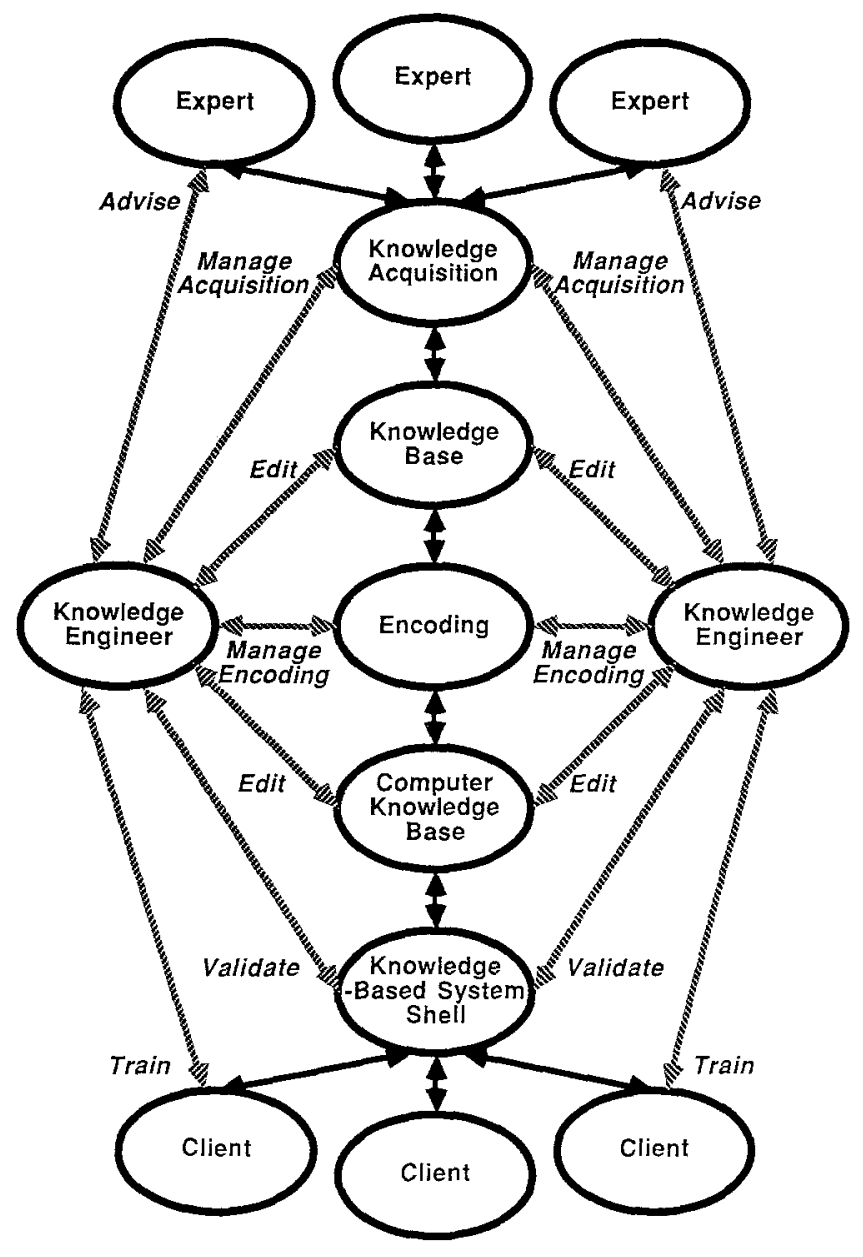

Figure 3. Knowledge engineers' roles in interactive computer-based knowledge acquisition.

This basic model has been greatly extended by the introduction of interactive knowledge acquisition and encoding tools allowing the expert to enter knowledge directly to the system without an intermediary. Such tools can greatly reduce the need for the knowledge engineer to act as an intermediary, but, in most applications, they leave a substantial role for the knowledge engineer.

As shown in Figure 3, knowledge engineers may:

- Advise the expert on the process of interactive knowledge elicitation

- Manage the interactive knowledge acquisition tools, setting them up appropriately

- Edit the partially encoded knowledge base in collaboration with the expert

- Manage the knowledge encoding tools, setting them up appropriately

- Edit the encoded knowledge base in collaboration with the expert 
- Validate the application of the knowledge base in collaboration with the expert

- Train the clients in the effective use of the knowledge base in collaboration with the expert by developing operational and training procedures

This use of interactive computer-based elicitation can be combined with manual elicitation and with the use of the interactive tools by the knowledge engineer rather than, or in addition to, the expert. The knowledge engineer can:

- Directly elicit knowledge from the expert

- Use the interactive elicitation tools to enter knowledge into the knowledge base

Figure 3 shows multiple knowledge engineers since the tasks above may require the effort of more than one person, and some specialization may be appropriate. Multiple experts are also shown since it is rare for one person to have all the knowledge required, and, even if this were so, comparative elicitation form multiple experts is itself a valuable knowledge elicitation technique.

Figure 3 also shows the complexity of the knowledge engineer's role and some of the support tools required. Figure 4 groups the support tools for editing, display, encoding, and validation of the knowledge bases into a Knowledge-Based System Support Environment

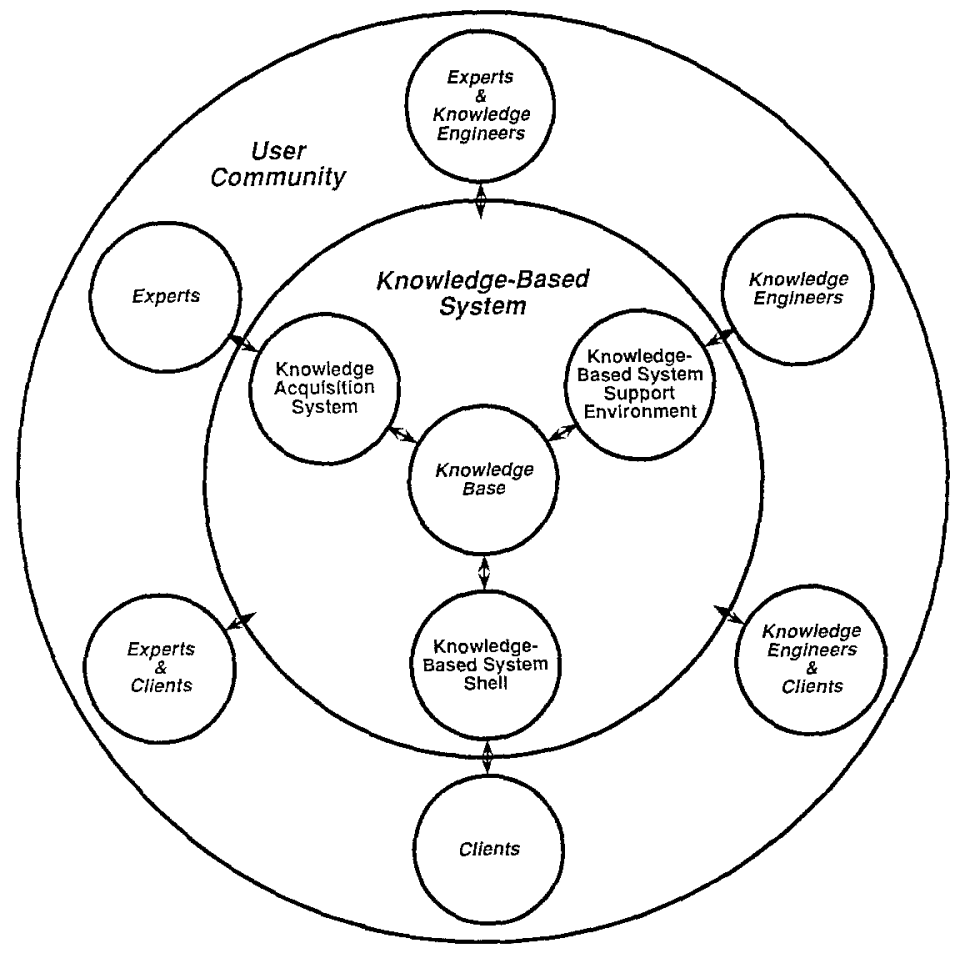

Figure 4. Major components of a knowledge based system. 
and combines the various forms of knowledge bases together. It shows the overall structure of a knowledge-based system as a central knowledge base interacting through the knowledge acquisition tools, the expert system support environment, and expert system shell, with a user community of experts, knowledge engineers, and clients.

The next section describes current knowledge acquisition tools and techniques.

\section{Knowledge Acquisition Tools and Techniques}

At the workshops, papers on knowledge acquisition tools and techniques discussed manual methods (for instance, protocol analysis), automated tools (traditional machine learning techniques), interactive computer-based tools, or combinations of these [Boose, 1989]. This section concentrates on the interactive tools.

One way to classify computer-based interactive knowledge acquisition tools is to associate them with knowledge-based application problems and problem-solving methods. Many tool developers describe their work in these terms. They feel that examining the roles that knowledge plays or the requirements of problem-solving methods structures tool development. This descriptive approach provides a framework for analyzing and comparing tools and techniques, shows the strengths and weaknesses of a method or tool, and focuses the knowledge acquisition process on the task of building useful knowledge-based systems.

Musen proposed that knowledge acquisition tools could be associated with specific problems or with specific problem-solving methods [Musen, 1987]. In a related manner, we have worked to classify tools with problems and problem-solving methods, since most problems are strongly linked to certain types of problem-solving methods. Consequently, certain types of domain knowledge and possibly control knowledge should be acquired to build the corresponding knowledge-based system. This idea was discussed at the First AAAISponsored Knowledge Acquisition for Knowledge-Based Systems Workshop held in Banff, Canada, in November, 1986 [Gaines and Boose, 1989]. Builders of interactive knowledge acquisition tools were asked to classify their research and the research of others in terms of these relationships.

Clancey [1986] introduced two hierarchies, one for application problems and one for problem-solving methods (Figure 5) [Boose, 1989]. Broadly, the problem hierarchy divides into analysis (interpretation) and synthesis (construction) problems. Generally, analysis problems involve identifying sets of objects based on their features. One typical characteristic of analysis problems is that a complete set of solutions can be enumerated and included in the system. Synthesis (generative or constructive) problems require that a solution be built up from component pieces or subproblem solutions. In synthesis problems there are often too many potential solutions to enumerate and include explicitly in the system.

High-level application problems include identification, prediction, control, design, specification, and modification assembly. Identification is further broken down into diagnosis and monitoring; design is broken down into configuration and planning. Presumably, lower levels in the problem hierarchy would be sub-problems (i.e., troubleshooting and symptom analysis would be found under diagnosis), and the leaves of the problem hierarchy would be specific application problems to be solved.

Problem-solving methods described by Clancey include heuristic classification and heuristic construction. Relationships exist between problems and these methods. For instance, 


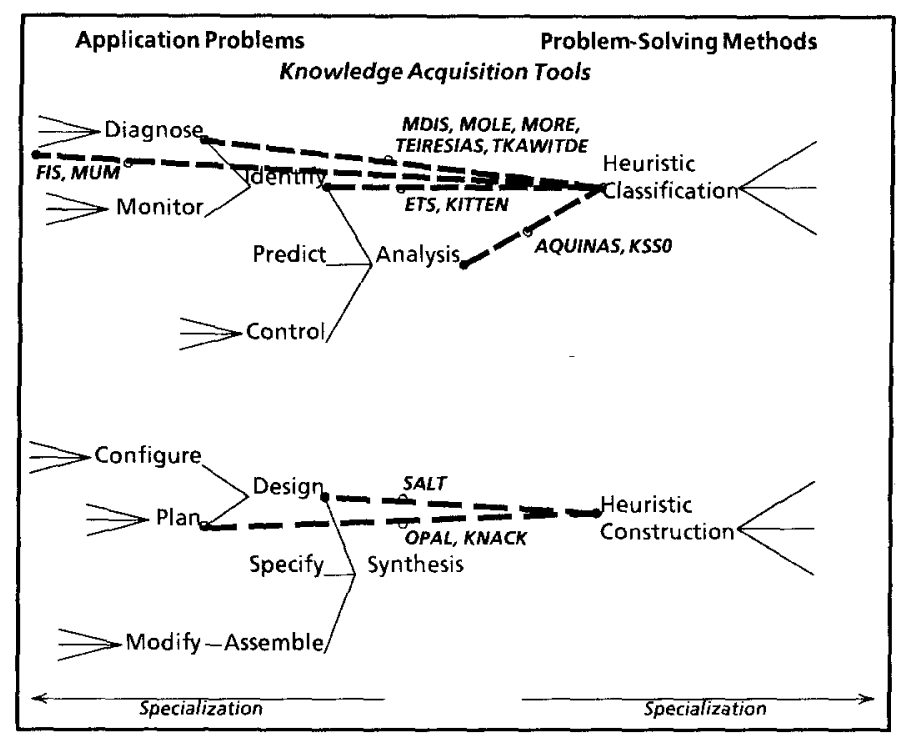

Figure 5. Knowledge acquisition tools may be associated with relationships between application problems and problem-solving methods. Representative tools shown above include are listed below (tools are discussed in more detail in Boose, 1989).

the heuristic classification problem-solving method has been used for many knowledge-based systems that solve analysis problems and is employed in a variety of knowledge-based system development tools, or "shells" (S.1, M.1, EMYCIN, TI-PC, and so on). In heuristic classification, data is abstracted up through a problem hierarchy, problem abstractions are mapped onto solution abstrations, and solution abstractions are refined down through the solution hierarchy into specific solutions.

General methods that have been applied to synthesis problems are sparse; Clancey classified these methods under heuristic construction. Usually, a specific method is developed to solve a particular problem (such as SALT's propose-and-revise method or OPAL's skeletal-planrefinement method), but it may be difficult to generalize the method. Some form of directed backtracking or cyclic constraint exploration is often used to explore the problem space.

Many problems require a combination of problem-solving methods. For instance, Clancey outlines a maintenance cycle requiring monitoring, prediction, diagnosis, and modification; this would combine aspects of heuristic classification and heuristic construction. Sometimes heuristic construction is used to solve analysis problems, and sometimes heuristic classification is used to structure portions of less complex synthesis problems.

The dashed lines in Figure 5 represent interactive knowledge acquisition tools that are associated with links between problems and problem-solving methods. Some tools are associated with high-level problems (Aquinas, KSS0), some are associated with sub-problem classes (MDIS, MOLE, SALT), and some are associated with specific application systems (FIS, MUM).

Representative tools shown in Figure 5 include: 
AQUINAS - elicit and model information using a knowledge acquisition workbench including hierarchically structured repertory grid-based interviewing and testing and other methods [Boose and Bradshaw, 1987b], [Kitto and Boose, 1987], [Boose and Bradshaw, 1987a], [Boose, 1988], [Bradshaw and Boose, 1989], [Kitto and Boose, 1988], [Shema and Boose, 1988], [Boose, Bradshaw, and Shema, 1988]

ETS-interview experts using repertory grid-based methods and test the knowledge [Boose, $1984,1985,1986 \mathrm{a}, \mathrm{b}]$

FIS-tie knowledge acquisition closely to the fault diagnosis domain [De Jong, 1987]

KITTEN - interview experts using repertory grid-based methods [Shaw and Gaines, 1987], [Shaw and Woodward, 1988]

KNACK-elicit and use knowledge about evaluation report generation [Klinker, Bentolila, Genetet, Grimes, and McDermott, 1987], [Klinker, Genetet, and McDermott, 1988]

KSS0-elicit knowledge with a repertory grid-based interviewing tool including text analysis, behavior induction, and psychological scaling techniques [Gaines, 1987a, 1987b, 1988], [Gaines and Sharp, 1987], [Shaw and Gaines, 1987], [Shaw, 1988]

MDIS-experts are interviewed to describe mechanisms in a top-down structured manner for diagnostic problems [Antonelli, 1983]

MOLE-exploit information about how problems are solved to elicit scarce diagnostic knowledge and use feedback to fine tune the knowledge [Eshelman, Ehret, McDermott, and Tan, 1987], [Eshelman, 1988]

MORE - exploit information about how problems are solved to elicit extensive diagnostic knowledge [Kahn, Nowlan, McDermott, 1985a, b]

MUM-evidential combination knowledge and control knowledge are elicited for medical problems [Gruber and Cohen, 1987]

OPAL-tie knowledge acquisition closely to the cancer treatment domain [Musen, Fagan, Combs, and Shortliffe, 1987]

SALT-elicit and deliver knowledge for constructive constraint satisfaction tasks [Marcus, McDermott, and Wang, 1985], [Marcus, 1987], [Stout, Caplain, Marcus, and McDermott, 1988]

TEIRESIAS --model existing knowledge to monitor refinements and help debug consultations [Davis and Lenat, 1982]

TKAW/TDE-exploit information about how problems are solved to elicit trouble-shooting knowledge [Kahn, Breaux, Joeseph, and DeKlerk, 1987]

Associations between problem domains and problem-solving methods help define the depth and breadth of current knowledge acquisition research. For example, Boeing's research using AQUINAS has led them to try to build a broad link (multiple integrated tool sets) between a general application problem class (analysis problems) and a powerful problemsolving method (heuristic classification). Other successful work has led researchers to tightly couple knowledge acquisition tools to a domain problem (for example FIS, STUDENT, OPAL).

Associations in the problem-method framework where no tools exist can point out promising areas for new research. For example, can special types of knowledge acquisition tools be associated with debugging problems and heuristic classification or with planning and new specializations of heuristic construction? 
A more detailed analysis of this classification, description of tools, and research strategies associated with them are contained in [Boose, 1989]. This study also lists manual techniques and automated (machine learning) techniques presented at the workshops and provides a catalog of tools and methods.

\subsection{Knowledge Acquisition Tool Dimensions}

Diverse interactive computer-based tools have been developed to assist the knowledge acquisition process. To help focus discussion at the first knowledge acquisition workshop, we used AQUINAS to classify the tools and develop tool dimensions. We present the results here to give an impression of similarity and differences among the tools.

Knowledge in AQUINAS is represented, in part, in networks of repertory grids. Objects appear along one axis of a grid and dimensions or traits appear along the other axis. AQUINAS helps the expert develop, analyze, refine, and test knowledge. A grid showing twenty-six interactive knowledge acquisition tools and associated analyses is shown in [Boose, 1989].

AQUINAS elicited the following set of interactive knowledge acquisition tool descriptors:

\section{Application task dimensions}

- Level of generality (domain dependence)-How domain-dependent is the tool?

- Analysis/synthesis-What broad categories of application tasks can the tool address?

- Specific problem-Has the tool been built for a specific problem? If so, what is the problem?

- Application statistics-(number and size of applications) - How many applications have been built with the tool? How diverse are they? How large are they? How much of the finished system did the tool help build?

Knowledge acquisition techniques and methods-What general knowledge acquisition techniques are employed?

\section{- Psychology-Based and Interviewing Methods}

- Automated/Mixed-initiative Interviewing-the tool interviews the expert

- Protocol analysis (Case Walk-Through/Eidetic Reduction/Observation/Process-Tracing) -record and analyze transcripts from experts thinking aloud during tasks

- Psychological Scaling (including multidimensional scaling)-use scaling techniques to help structure knowledge

- Repertory Grids/PCP_-use personal construct psychology and related methods to elicit and analyze knowledge

- Task/Method/Performance Exploitation

- Domain Exploitation (Single Application) - rely heavily on the domain for knowledge acquisition guidance

- Problem-Solving Method Exploitation-use information about the problem-solving method to guide knowledge acquisition 
- Performance System (direct link or embedded)-generate knowledge that may be directly tested and used

\section{- Modeling}

- Decision Analysis-perform probabilistic inference and planning using influence diagrams

- Modeling (deep models, causal models, cognitive models, conceptual models, mediating representations, task-level models)-use or generate models of the domain, possibly independent of a tool or a specific application

- Consistency Analysis-analyze knowledge for consistency

- Physical Model Simulation-use basic laws to derive physical models through simulation

- Multiple Experts

- Delphi-gather information from people independently

- Multiple Source-elicit and analyze knowledge from multiple sources separately and combine for use

- Other Sources of Knowledge

- Textual Analysis/Natural Language Analysis-generate knowledge directly by analyzing text Modeling dimensions

- Deep Modeling/Shallow Modeling-Are "deep" models or "causal" models elicited?

- Multiple/Single Methods for Handling Uncertainty-What techniques, if any, are used to model uncertainty?

\section{Representations}

- Expertise representation method ("intermediate" representation) (structures, hierarchies, operators, probability distributions, relations, repertory grids, rules, scripts, tables)

- Knowledge types (causal knowledge, classes, conceptual structures, constraints, control, covering, example cases, explanations, facts, goals, judgments, justifications, preferences, procedures, relations, spatial, strategic, temporal, terminology, uncertainties)

\section{Features}

- High-level techniques/low-level techniques-How sophisticated are the techniques used?

- Learning component (automatic, interactive, none)-If there is a learning component in the tool, how powerful is it? Is it automatic or interactive?

- Multiple features/few features-How many techniques are integrated in a single framework? How well do multiple techniques support each other?

- Multiple knowledge sources support-Is there specific support for eliciting, analyzing, or delivering knowledge from multiple experts or other sources?

- Multiple knowledge views/few knowledge views-How many ways are there to look at elicited knowledge? What, if any, knowledge transformation techniques are employed?

\section{System use}

- Automated tool/semi-automated tool/manual technique-How much of the technique is implemented as a computer program? How "smart" is the tool? Is effective tool use dependent on the user, or does the tool offer semi-automated or automated assistance? 
- Efficiency of use; speed of use-How hard is the tool to use? How efficient is knowledge elicitation and modeling? How well are the techniques implemented?

- Implementation stage (planned, in progress, implemented, tested, in use, past use)

- Intended users (end-users of expert system, decision makers, experts, knowledge engineers, AI programmers needed)-Who are the targeted users of the tool?

- Life cycle support (one-shot use to complete cycle support)-How much of the knowledge engineering and system delivery life cycle does the tool support?

- System in use/system not in use-Is the tool currently in use? Was the tool previously in use? Will the tool be in use in the future?

- Training needed-How much training is needed to use the tool? Can experts use the tool directly?

- Validation, verification, maintenance--Does the tool offer support for testing and maintenance?

AQUINAS performed several analyses of the knowledge. For example, an implication analysis produced by AQUINAS showed logical entailments between different dimensions. A similarity analysis among dimensions showed, for example, that EFFICIENT.AND.FAST.TO.USE was closely coupled to LITTLE.TRAINING. NEEDED. A similarity analysis among tools showed, for example, high similarity between ETS, KITTEN, and PLANET, and low similarity between FIS and KSSO (similarity scores were produced for each pair of dimensions and each pair of tools).

AQUINAS also produced several "scatter tables" showing clusters of tools plotted on successive pairs of dimensions. A simplified version of one of these tables, domain independence vs. task class, is shown in Figure 6 . The table shows concentrations of interactive knowledge acquisition tools for diagnostic tasks, but the few knowledge acquisition toois

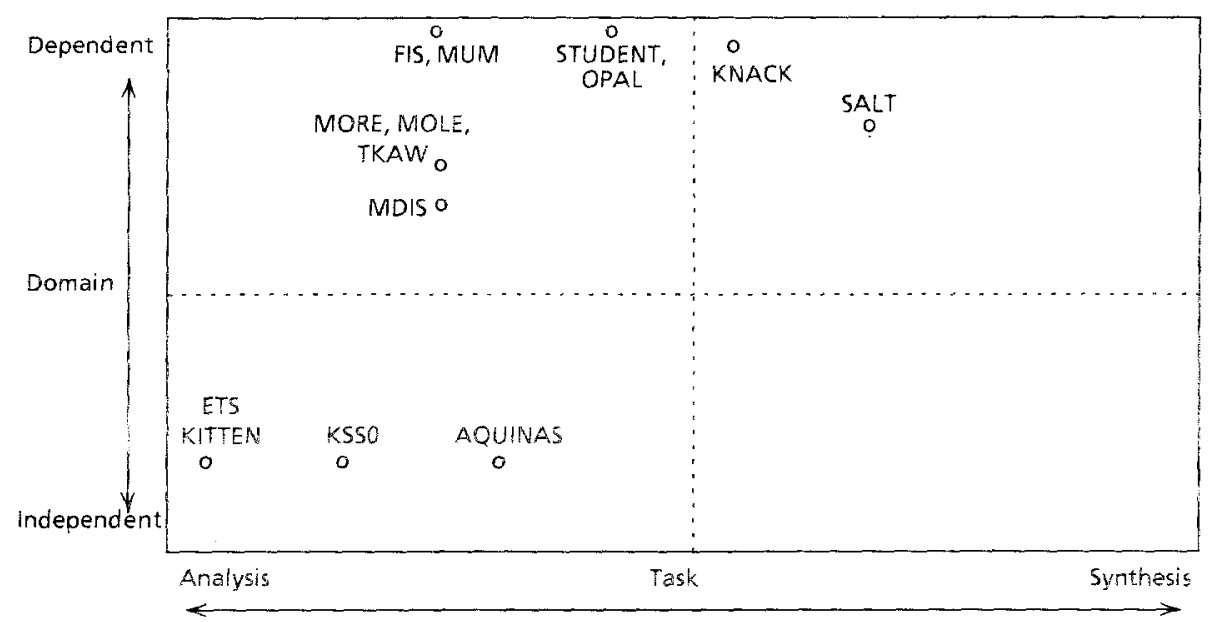

Figure 6. AQUINAS interactive knowledge acquisition tool scatter table for domain independence vs. task class. The table shows concentrations of interactive knowledge acquisition tools for diagnostic tasks, but the few knowledge acquisition tools that exist for synthesis probems are domain-dependent. 
that exist for synthesis problems are domain-dependent. Other example tables showed that, generally, it is easier to build automated tools that are more domain-dependent; that, generally, automated knowledge acquisition tools are easier to learn how to use than less automated tools; and that knowledge acquisition tools that support more of the knowledge engineering life cycle tend to be more domain-dependent.

Other patterns in the tools are apparent. For instance, some tools try to draw power using strong specific domain knowledge (FIS, OPAL, MUM); other tools try to address a broader range of problems at the expense of built-in domain-specific problem-solving power (ETS, KITTEN, AQUINAS). The few tools that address synthesis problems are domain dependent. Most researchers seem to be interested in applying their tools to more domain independent and/or harder tasks.

Success in implementing interactive knowledge acquisition tools for particular problems seems to follow success at building large numbers of knowledge-based systems in that domain. Once many systems exist, patterns become apparent that may be exploited by specialized knowledge-based system shells, and in turn, by knowledge acquisition tools. For example, many diagnostic knowledge-based systems exist, specialized diagnostic shells are appearing, and we see a strong concentration of knowledge acquisition tools in this area. As more specific synthesis knowledge-based systems are built and useful specialized shells emerge for these kind of problems, we should expect to see more knowledge acquisition tools for synthesis problems.

\subsection{Knowledge Acquisition Workshops and Related Publications}

We are attempting to make the knowledge acquisition workshop materials as widely available as possible. The following section details the availability of publications from each workshop and from a new Academic Press knowledge acquisition journal. If you have related questions contact Brian Gaines (gaines@calgary.cdn) or John Boose (john@atc.boeing.com).

First AAAl-Sponsored Knowledge Acquisition for Knowledge-Based Systems Workshop (KAW86), Banff, November 1986

Preprints distributed to attendees only.

Revised and updated papers published in the International Journal of Man-Machine Studies, January, February, April, Augusi, and September 1987 special issues. Papers plus editorial fnaterial and index collected in two books in the Knowledge-Based Systems Series: Gaines, B.R. and Boose, J.H. (Eds) Voi. 1: Knowleơge Acquisition for Knowledge-Based Systems. London: Fcademic Press, 1988. Boose, J.H. and Gaines, B.R. (Eds) Vol. 2: Knowledge Acquisition Tools for Exper Systems. London: Academic Press, 1988.

Frst European Knowledge Acquisition for Knowledge-Based Systems Workshop (EKAW87), Reading, UK, September 1987

Froceedings available as: Proceedings of the Firsi European Workshop on Knowledge Acquisition for Knowiedge-Based Systems. Sent sterling money order or draft for 39.00 pounds payabie to University of Reading to: Prof. T.R. Addis, Department of Computer Science, University of Reaouns, Whitekmghts, PO Box 220, Reading RG6 2AX, UK. 
Second AAAI-Sponsored Knowledge Acquisition for Knowledge-Based Systems Workshop (KAW87), Banff, October 1987

Preprints distributed to attendees only.

Revised and updated papers being published in the International Journal of Man-Machine Studies, 1988 regular issues (August, September, October, November, December, and others). Papers plus editorial material and index will be collected in book form for the Knowledge-Based Systems Series, together with other knowledge acquisition papers from IJMMS. These will be available in Fall, 1989: Gaines, B.R. and Boose, J.H. (Eds) Vol. 3: Machine Learning and Uncertain Reasoning in Knowledge-Based Systems. London: Academic Press, 1989. Boose, J.H. and Gaines, B.R. (Eds) Vol. 4: Knowledge Acquisition: Foundations. London: Academic Press, 1989.

Second European Knowledge Acquisition for Knowledge-Based Systems Workshop (EKAW88), Bonn, West Germany, June 1988

Proceedings available as: Boose, J.H., Gaines, B.R., and Linster, M. (Eds), Proceedings of the European Workshop on Knowledge Acquisition for Knowledge-Based Systems (EKAW88). Send order to (the GMD will invoice you for DM68.00 plus postage): Marc Linster, Institut fur Angewandte Informationstechnik der Gesellschaft fr Mathematik und Datenverarbeitung mbH, Schloss Birlingoven, Postfach 1240, D-5205 Sankt Augustin 1, West Germany.

Third AAAI-Sponsored Knowledge Acquisition for Knowledge-Based Systems Workshop (KAW88), Banff, November 1988

Proceedings/preprints available as: Boose, J.H. and Gaines, B.R. (Eds), Proceedings of the 3rd Knowledge Acquisition for Knowledge-Based Systems Workshop. Send money order, draft, or check drawn on US or Canadian bank for US\$65.00 or CDN\$85.00 to: SRDG Publications, Department of Computer Science, University of Calgary, Calgary, Alberta, Canada T2N 1N4. Revised and updated papers will be published in the International Journal of Man-Machine Studies, 1989 regular issues, and possibly in the proposed Academic Press journal, Knowledge Acquisition for Knowledge-Based Systems. Papers plus editorial material and index will be collected in book form, together with other knowledge acquisition and related papers from IJMMS and KAKBS in 1990.

Information about proceedings and publications from the workshops below will be available later; get in touch with the listed contact for future information.

Third European Knowledge Acquisition for Knowledge-Based Systems Workshop (EKAW89), Paris, France, July 1989

Contact Jean-Gabriel Ganascia, LAFORIA, Univ. Pierre et Marie Curie, Tour 45-46, 4 Place Jussieu, 75230 Paris Cedex 05; (32)-1-69 416626.

Fourth AAAI-Sponsored Knowledge Acquisition for Knowledge-Based Systems Workshop (KAW89), Banff, October 1-6 1989

Contact Brian Gaines (address above). 
Fourth European Knowledge Acquisition for Knowledge-Based Systems Workshop (EKAW90), The Netherlands, Summer, 1990

Contact Bob Wielinga, Department of Social Science Informatics, University of Amsterdam, Herengracht 196, 1016 BS Amsterdam, The Netherlands.

Fifth AAAI-Sponsored Knowledge Acquisition for Knowledge-Based Systems Workshop (KAW90), Fall, 1990

Information about proceedings and publications from this workshop will be available in the future. Contact Brian Gaines (address above).

First Japan Knowledge Acquisition for Knowledge-Based Systems Workshop (JKAW90), Fall, 1990

Contact Hiroshi Motoda, Advanced Research Laboratory, Hitachi, Ltd., Kokubunji, Tokyo 185, Japan.

Journal: Knowledge Acquisition: An International Journal of Knowledge Acquisition for Knowledge-Based Systems, Academic Press, Editors: Brian R. Gaines and John H. Boose, first publication in March, 1989.

Aims: Knowledge Acquisition aims to provide those developing knowledge-based systems with access to state-of-the-art research on tools, techniques, methodologies, and foundations for knowledge acquisition from experts, texts, and other sources of human knowledge processes through advanced knowledge-based systems, and particularly on the elicitation and modeling of knowledge in those systems derived from more conventional sources. The emphasis is not on artificial intelligence but on the extension of natural intelligence through knowledge-based systems.

\section{Coverage}

Elicitation/modeling of expertise: systems that obtain and model knowledge from experts. Elicitation/modeling of expertise: manual knowledge acquisition methods and techniques. Apprenticeship, explanation-based, and other learning systems; integration of such systems with other knowledge acquisition techniques.

Integration of knowledge from multiple experts or other sources; issues in collaborative knowledge-based systems.

Issues in cognition and expertise that affect the knowledge acquisition process.

Extracting and modeling of knowledge from text.

Integration of knowledge acquisition techniques within a single system; integration of knowledge acquisition systems with other systems (hypermedia, database management systems, simulators, spreadsheets).

Knowledge acquisition methodology and training.

Validation of knowledge acquisition techniques; the role of knowledge acquisition techniques in validating knowledge-based systems. 


\section{References}

Antonelli, D. 1983. The application of artificial intelligence to a maintenance and diagnostic information system (MDIS). Proceedings of the Joint Services Workshop on Artificial Intelligence in Maintenance. Boulder, CO.

Boose, J.H. 1984. Personal construct theory and the transfer of human expertise. Proceedings of the National Conference on Artificial Intelligence (AAAI-84), p. 27-33, Austin, Texas.

Boose, J.H. 1985. A knowledge acquisition program for expert systems based on personal construct psychology. International Journal of Man-Machine Studies, 23, 495-525.

Boose, J.H. 1986a. Expertise Transfer for Expert System Design, New York: Elsevier.

Boose, J.H. 1986b. Rapid acquisition and combination of knowledge from multiple experts in the same domain. Future Computing Systems Journal, 1, 191-216.

Boose, J.H. 1988. Uses of repertory grid-centred knowledge acquisition tools for knowledge-based systems. Internationai Journal of Man-Machine Studies, 29, 287-310.

Boose, J.H. 1989. A survey of knowledge acquisition techniques and tools. Knowledge acquisition: An international journal of knowledge acquisition for knowledge-based systems, in press, Vol. 1, No. 1.

Boose, I.H., and Bradshaw, I.M. 1987a. Expertise transfer and complex problems: using Aquinas as a knowledge acquisition workbench for expert systems. Special issue on the 1st Knowledge Acquisition for Knowledge-Based Systems Workshop, 1986, Part 1, International Journal of Man-Machine Studies, 26, 3-28; also in Boose, J.H., and Gaines, B.R. (eds), Knowledge-based systems Vol. 2: Knowledge acquisition tools for expen systems. New York: Academic Press, 1988.

Boose, I.H., and Bradshaw, I.M. 1987b. AQUINAS: A knowledge acquisition workbench for building knowledgebased systems. Proceedings of the First European Workshop on Knowledge Acquisition for Knowledge-Based Systems (pp. A6.1-6). Reading University.

Boose, J.H., Bradshaw, J.M., Shema, D.B. 1988. Recent progress in Aquinas: A knowledge acquisition workbench. Proceedings of the Second European Knowledge Acquisition Workshop (EKAW-88). p. 2.1-15, Bonn.

Bradshaw, $J$. 1988. Shared causal knowledge as a basis for communication between expert and knowleoge acquisiion system. Froceedings of the Second European Knowledge Acquisition Workshop (EKAW-88) pp. 12.1-6.

Bradshaw, J.M. 1988. Strategies for selecting and interviewing expers. Eoeing Computer Services Technical report, in preparation.

Bradshaw, J.M., and Boose, J.H. 1989. Decision analytic techniques for knowledge acquisition: Combining situation and preference models using Aquinas. Special issue on the 2 nd Knowledge Acquisition for Knowledge-Based Systems Workshop, 198\%, International Journal of Man-Machine Studies, in press.

Clancey, W. 1986. Heuristic classiñcation. In J. Kowalik (Ed.). Knowledge-based problent-solving. New York: Prentice-Hall.

Davis, R., and Lenat, D.B. 1982. Knowledge-based systems in artificial intelligence. New York: McGraw-Hill. DeJong, K. 1987. Knowledge acquisition for fault isolation expert systems. Special issue on the lst AAAI Knowledge Acquisition for Knowledge-Based Systems Workshop, 1986, Pari 4, International Journai of Man-Machine Studies, Voi. $27, \mathrm{No}, 2$.

Eshelman, L, Ehret, D., MeDermot, i., and Tan, M. 1987. WOLE: A Penacious knowledge acquisition tool. Special issue on the 1si AAR Knowledge Acquisition for Knowledge-Based Systems Workshop, 1986, Part 1 . International Joumal of Man-Machine Studies, 26, 41-54; also in Boose. J.H., and Gaines, B.R. (Fds), Knowledgebased systems Vol. 2: Knowledge acquisition tools for expert systems, New York: Academic Press, 1988.

Eshelman, L. 1988. MOLE: A knowledge acquisition wol that buries certainty factors. Special issue on the 2 nd Knowledge Acquisition for Knowiedge-Based Systems Workshop, 988 , hiemational Journal of Man-Machine Studies, in press.

Gaincs, E.R. 1987a. An overview of knowledge acquisition and transfer. Special issue on the 1st Knowledge Acquisition for Knowledge-Based Systems Workshop, 1986, Part 3, International Joumal of Man-Machine Studies, 26, 453-472; also in B.R. Gaines and J.H. Boose (Eds), Knowledge-based systems Vol. 1: Knowledge acquisition for knowieage-based systems. New York: Academic Press.

Gaines, B.R. 19875. Knowledge acquistion for expert sysiens. Proceedings of the First European Workshop on

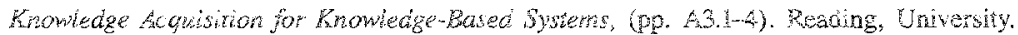

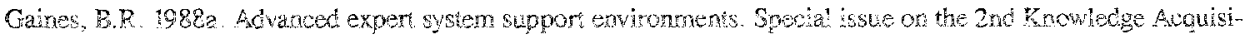
tion for Knowledge-Based Systems Workshop, 1987, Maternational Joumal of Mar-Machine Studies, in press. 
Gaines, B.R. 1988b. Second generation knowledge acquisition systems. Proceedings of the Second European Knowledge Acquisition Workshop (EKAW-88), (pp. 17.1-14). Bonn.

Gaines, B.R., and Boose, J.H. 1989. A summary of the AAAI-sponsored knowledge acquisition for knowledgebased system workshops. AI Magzine, in press.

Gaines, B.R. and Sharp, M. 1987. A knowledge acquisition extension to notecards. Proceedings of the First European Workshop on Knowledge Acquisition for Knowledge-Based Systems, (pp. C1.1-7). Reading University.

Gruber, T.R., Cohen, P.R. 1987. Design for acquisition: Principies of knowledge system design to facilitate knowledge acquisition. Special issue on the 1st Knowledge Acquisition for Knowledge-Based Systems Workshop, 1986, Part 2, International Journal of Man-Machine Studies, 26, 143-160; also in J.H. Boose and B.R. Gaines (Eds), Knowledge-based systems Vol. 2: Knowledge acquisition tools for expert systems. New York: Academic Press.

Kahn, G., Nowlan, S., and McDermott, I. 1985a. Strategies for knowledge acquisition. IEEE Transactions of Pattern Analysis and Machine Intelligence, PAMI-7 (3), 511-522.

Kahn, G., Nowlan, S., and McDermott, J. 1985b. MORE: An intelligent knowledge acquisition tool. Proceedings of the Ninth Joint Conference on Artificial Intelligence, (pp. 581-584). Los Angeles, CA.

Kahn, G.S., Breaux, E.H., Joeseph, R.L., and DeKlerk, P. 1987. An intelligent mixed-initiative workbench for knowledge acquisition. Special issue on the 1st AAAI Knowledge Acquisition for Knowledge-Based Systems Workshop, 1986, Part 4, International Journal of Man-Machine Studies, 27, 167-180; also in J.H. Boose and B.R. Gaines (Eds), Knowledge-based systems Vol.2: Knowledge acquisition tools for expert systems. New York: Academic Press.

Kitto, C.M., and Boose, J.H. 1987. Heuristics for expertise transfer: The automatic management of complex knowledge acquisition dialogs. Special issue on the 1st Knowledge Acquisition for Knowledge-Based Systems Workshop, 1986, Part 2, International Journal of Man-Machine Studies, 26, 183-202; also in J.H. Boose and B.R. Gaines (Eds), Knowledge-based systems Vol. 2: Knowledge acquisition tools for expert systems. New York: Academic Press.

Kitto, C.M., and Boose, J.H. 1988. Selecting knowledge acquisition tools and strategies based or application characteristics. Special issues on the 2nd Knowledge Acquisition for Knowledge-Based Systems Workshop, 1987, International Journal of Man-Machine Studies, in press.

Klinker, G., Bentolila, J., Genetet, S., Grimes, M., and McDermott, J. 1987. KNACK: Report-driven knowledge acquisition. Special issue on the 1st AAAI Knowledge Acquisition for Knowledge-Based Systems Workshop, 1986, Part 1, Internationai Joumal of Man-Machine Studies, 26, 65-80; also in J.H. Boose and B.R. Gaines (Eds), Knowledge-based systems Vol. 2: Knowledge acquisition tools for expert systems. New York: Academic Press.

Klinker, G., Genetet, S., and McDermott, J. 1988. Knowledge acauisition for evaluation systems. Special issue on the 2nd Knowledge Acquisition for Knowledge-Based Systems Workshop, 1987, International Journal of Man-Machine Studies, in press.

Marcus, S., McDermott, J., and Wang, T. 1985. Knowledge acquisition for constructive systems. Proceedings of the Ninth Joint Conference on Artificial Intelligence, (pp. 637-639). Los Angeles, CA.

Marcus, S. 1987. Taking backtracking with a grain of SALT. Special issue on the ist Knowledge Acquisition for Knowledge-Based Systems Workshop, 1986, Part 2, Intenationei Iownal of Wan-Machine Strales, 26, 383-398; also in I.H. Boose and B.R. Gaines (Eds), Knowledge-based sustems Vol. 2: Knowledge acunisition tools for expert systems. New York: Academic Press.

Musen, M.A. Fagan, L.M. Combs, D.M. and Shortife, E.H. 1987 Use of domain model to drive an interactive knowledge-editing tool. Speciai issue on the lst AAAi Knowledge Acquisition for Knowledge-Based

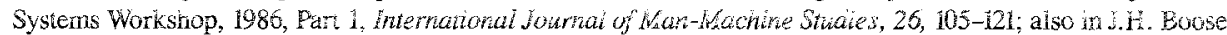
and B.R. Gaines (Eás), Knowledge-based sysrems Vol. 2; Knowledge acquisition tools for expert sysiems. New York: Academic Press.

Shaw, M.L.G. 1988. Problems of validation in a knowledge acquisition system using multiple experts. Proceedings of the Second European Knowledge Acquisition Workshop (EKAW-88), (pp 5.1-15). Bonn.

Sraw, M.L.G., and Gaines, B.R. 1987. Techniques for knowledge acquisition and transfer. Special issue on the ist Knowjedge Acquisition for Knowledge-Based Systems Worishop. 1986, Part 5 , kntemationat Journat of Man-Machine Studies, 27, 25t-280

Shaw. M.L.G., and Woodward, J.B. 1988. Validation in a knowledge support system: Construing consistency with multiple experts. Special issue on the 2nd Knowledge Acquisition for Knowledge-Based Systems Workshop, 1987, internationat Journai of Man-Machine Studies, 29, 329-350. 
Shema, D.B., and Boose, J.H. 1988. Refining problem-solving knowledge in repertory grids using a consultation mechanism. Special issue on the 2nd Knowledge Acquisition for Knowledge-Based Systems Workshop, 1987, International Journal of Man-Machine Studies, 447-460.

Stout, J., Caplain, G., Marcus, S., and McDermott, J. 1988. Toward automating recognition of differing problemsolving demands. Special issue on the 2nd Knowledge Acquisition for Knowledge-Based Systems Workshop, 1987, International Journal of Man-Machine Studies, in press. 